\title{
TRIBUNAL PENAL INTERNACIONAL: PERCEBENDO SUA IMPORTÂNCIA MUNDIAL
}

Fabiana Vergílio Souto, Israel Matheus Cardozo Silva Coutini, Shirley Oliveira Lima Nomura, Thais Fernanda Silva Rogério.

Universidade do Oeste Paulista - UNOESTE, Curso de Direito. E-mail: israelmatheus2010@hotmail.com.

\section{RESUMO}

Esta obra tratou do Tribunal Penal Internacional e, consequentemente, de seu Estatuto (Estatuto de Roma do Tribunal Penal Internacional). Logo, o objetivo deste estudo foi demonstrar, ao leitor, o que é o Tribunal Penal Internacional e a importância de se conhecer desta instituição pouco estudada pelos autores, além de evidenciadas as noções sobre as principais dúvidas que decorrem desta no que tange ao direito brasileiro, especialmente sua aplicabilidade frente à Constituição Federal de 1988. A metodologia constou de diversas obras dos mais populares autores brasileiros das áreas de Direito Internacional, Direito Constitucional e, inclusive, Direito Penal Militar. Os resultados foram persuasivos, ainda que tenha sido difícil encontrar obras que ao menos citasse o Tribunal Penal Internacional. Conclui-se que o Tribunal Penal Internacional é uma instituição autônoma e permanente de grande importância à prevalência dos direitos humanos, tão discutidos atualmente.

Palavras-chave: Tribunal Penal Internacional, Estatuto de Roma, Direito Internacional, Tratado, Constituição Federal.

\section{INTERNATIONAL CRIMINAL COURT: PERCEIVING IMPORTANCE OF YOUR WORLD}

\begin{abstract}
This work dealt with the International Criminal Court and, consequently, of its Statute (Rome Statute of the International Criminal Court). Therefore, the aim of this study was to demonstrate to the reader, which is the International Criminal Court and the importance of knowing this little institution studied by the authors, and highlighted the notions of the main questions arising from this in relation to Brazilian law especially its application against the Federal Constitution of 1988. The methodology consisted of several works of the most popular Brazilian authors in the areas of international law, constitutional law and even Military Penal Law. The results were compelling, although it was difficult to find works that at least quoting the International Criminal Court. It concludes that the International Criminal Court is an autonomous and permanent institution of great importance to the prevalence of human rights, as currently discussed.

Keywords: International Criminal Court, the Rome Statute, International Law, Treaty, Federal Constitution.
\end{abstract}

\section{INTRODUÇÃO}

Com o avanço da mídia e outros meios informativos, muito se tem falado em Direitos Humanos. Basicamente, quando se trata de punir alguém por determinada conduta ilícita cominada legalmente, fala-se de condições humanas que tal punição pode gerar ao acusado, a estrutura do ambiente em que será mantido encarcerado, se realmente seria o meio mais eficaz de se punir, como a sociedade reage, entre outras considerações.
O que os estudiosos atuais não se atêm, isto é, deixam passar sub-repticiamente, referese ao Tribunal Penal Internacional, que se trata de uma instituição que representa grande avanço para a humanidade e, consequentemente, para os Direitos Humanos. Assim, poder-se-ia até questionar o porquê desta instituição não ser tão destacada na doutrina contemporânea, já que o tema Tribunal Penal Internacional é de grandes dimensões.

O objetivo deste estudo foi, em primeiro plano, demonstrar noções e aspectos gerais do 
Tribunal Penal Internacional, além de apresentar sua historicidade. Num segundo momento, ponderar sobre as principais características desta Corte como instituição autônoma (competência, composição e órgãos); não obstante, delinear sobre a aplicabilidade de seu estatuto no Direito Constitucional pátrio e supostas incompatibilidades do mesmo.

\section{TRIBUNAL PENAL INTERNACIONAL - ASPECTOS GERAIS}

O Tribunal Penal Internacional (ou Corte Penal Internacional) é uma instituição permanente e independente, criada pelo Tratado de Roma (também conhecido como Estatuto de Roma), de 17 de julho de 1998, e entrou em vigência a partir do dia 10 de julho de 2002. Sua sede localiza-se em Haia, na Holanda - apesar do nome do Tratado possuir o termo "Roma". Suas funções primordiais é julgar crimes de incomensurável gravidade, como os genocídios, crimes de guerra, crimes contra a humanidade e crimes de agressão, conforme dispõe seu estatuto; e priorizar os direitos humanos no âmbito jurídico-internacional - esta função é consequência daquela.

À época de sua inserção, o Tribunal Penal Internacional foi assinado por mais de 100 países; atualmente, 122, mas nem todos são ratificados, isto é, alguns são apenas membros. Podem-se destacar, então, alguns dos países mais influentes da atualidade que se submetem ao TPI. Eis os destaques: Alemanha, Itália, França, Espanha, Portugal, África do Sul, Japão, Canadá, Argentina, Nova Zelândia, entre outros ${ }^{1}$. Resumidamente, são 43 signatários da Europa, 27 da América, 34 da África e 18 da Ásia.

Não se impõe aos Estados (no sentido amplo da palavra) a obrigação de serem signatários do TPI. Do mesmo modo, já o sendo, não há obrigação de nele permanecer.

Diante desta breve disposição, vem-se a seguinte indagação: está o Brasil entre os 122 países signatários? Esta e outras indagações serão tratadas no próximo item.

\section{O BRASIL É MEMBRO DO TPI?}

De imediato, a resposta só pode ser afirmativa, já que a Constituição Federal de 1988 prevê, em seu art. 5ㅇ, § 4으, que "O Brasil se

\footnotetext{
${ }^{1}$ Cf. O Estatuto de Roma entrou em vigor em 10 de julho de 2002, após ser ratificado por 60 países. Atualmente, o Estatuto possui a adesão de mais de 100 países, com as notáveis ausências da China e dos Estados Unidos (BIANCHINI; GOMES, 2012, p. 131).
}

submete à jurisdição do Tribunal Penal Internacional a cuja criação tenha manifestado adesão". Não obstante, no Brasil foi promulgado o Decreto no 4.388 de 25 de setembro de 2002, denominado Estatuto de Roma do Tribunal Penal Internacional, no qual contém todas as disposições e normas a serem seguidas pelo Poder Judiciário pátrio acerca dessa Corte (BRASIL. Constituição, 1988).

Para o Brasil - aliás, não só para este trata-se de grande mérito ser membro do TPI; um ato que visa a suprir a impunidade de quem é protagonista de crimes bárbaros, apesar de não ser corriqueira a prática dos mesmos. Assim, a criação do Tribunal Penal Internacional.

[...] representa grande
avanço tanto do direito
material, como dos
mecanismos institucionais
do direito internacional, no
contexto pós-moderno. Este
conjunto normativo e
institucional é também
relevante por consolidar a
condição do ser humano,
como sujeito de direito
internacional (ACCIOLY et al.,
p. 847, 2016). (sic)

Vale frisar que o supracitado $\S 40$ do art. 5o não se originara juntamente com a Carta Maior; fora acrescentado pela Emenda Constitucional no 45, de 8 de dezembro de 2004 pela reforma do Poder Judiciário, portanto (BRASIL, 2014).

\section{TRIBUNAIS INTERNACIONAIS AD HOC}

O TPI não é o primeiro Tribunal a ser posto para julgar um ou alguns dos crimes já mencionados. Em alguns momentos da história foram criados Tribunais com a mesma função. Foram inúmeros casos, mas pode-se citar dois deles, criados pelo Conselho de Segurança das Nações Unidas: o para julgar os crimes dos conflitos na Antiga lugoslávia (datado de 1993), e - para julgar o genocídio e outros crimes cometidos em Ruanda (datado de 1994).

Trindade $^{2}$ (2013, p. 33), comentando sobre os Tribunais supracitados, lembra que os

\footnotetext{
2 Professor Emérito de Direito Internacional da Universidade de Brasília; Professor Titular de Direito Internacional do Instituto Rio Branco (1978-2009); Professor Honorário da Universidade de Utrecht; Honorary Fellow da Universidade de Cambridge; ExPresidente da Corte Interamericana de Direitos Humanos; Juiz da
} 
mesmos contribuíram para a "[...] luta contra a impunidade de criminosos de guerra e de responsáveis por atos de genocídio e crimes contra a humanidade, superando assim uma das carências do Direito Internacional clássico". (sic)

É importante destacar que todos os Tribunais Penais Internacionais anteriores ao regulado pelo Estatuto de Roma foram criados apenas e tão somente para aquele momento. São denominados Tribunais ad hoc, isto é, cria-se a Corte para julgar os crimes do local e, após todo o procedimento, extingue-se (isto conforme a previsão de seu Estatuto). Assim, v.g., o Tribunal que julgara o conflito em Ruanda não mais existe. Já o para a ex-lugoslávia, mantém-se em atividade, pois ainda não julgara todas as condutas atentadas.

Foram os últimos Tribunais ad hoc criados. O resultado positivo na instituição destas Cortes temporárias foi o impulso necessário à criação do presente TPI. Em suma, a grande diferença entre o atual e os outros TPIs é a característica de ser instituição permanente, isto é, não ser ad hoc.

\section{A COMPETÊNCIA DO TPI}

O exercício efetivo das funções do Tribunal Penal Internacional foi iniciado em 10 de julho de 2002. Desde então, esta instituição de direito internacional tem competência para julgar crimes cometidos por pessoas contra o Estado e de pessoas contra pessoas ${ }^{3}$. Logo, "O Tribunal Penal Internacional possui jurisdição transnacional sobre indivíduos, inclusive militares, que tenham praticado ou participado dos crimes previstos no Estatuto de Roma." (BIANCHINI; GOMES, 2012, p. 132-133)

Portanto, os crimes de competência do TPI estão previstos no art. 5o do ERTPI e são os seguintes: crimes de genocídio (alínea $a$ ), crimes contra a humanidade (alínea $b$ ), crimes de guerra (alínea c) e crimes de agressão (alínea d). (BRASIL, 2002)

\section{COMPOSIÇÃO - ÓRGÃOS E MEMBROS}

Quanto aos Órgãos que compõem o TPI, conforme o art. 34 do citado Estatuto, podem ser

\footnotetext{
Corte Internacional de Justiça (Haia); Ex-Consultor Jurídico do Ministério das Relações Exteriores (1985-1990); Membro Titular do Institut de Droit International, e do Curatorium da Academia de Direito Internacional da Haia.

${ }^{3}$ A competência de julgamento do Tribunal Penal Internacional é ratione temporis (art. 11 do ERTPI), isto é, abrange apenas condutas praticadas a partir de 1.ㅇ de julho de 2002.
}

classificados da seguinte forma: a) Presidência responsável pela administração geral do tribunal; b) uma Seção de Recursos, uma Seção de Julgamento em Primeira Instância e uma Seção de Instrução; c) gabinete do Procurador; e d) Secretaria.

No Brasil, os tribunais costumam ser compostos por determinada quantidade de desembargadores ou ministros, eleitos por um período determinado na lei (v.g., Superior Tribunal de Justiça, com trinta e três membros; Supremo Tribunal Federal, com onze membros). No TPI não se foge à regra, pois compõe-se de dezoito juízes (art. 36 do ERTPI), com mandato de nove anos, mas vedada a reeleição, não podendo, ainda, um membro ser da mesma nacionalidade de outro.

Assim, também não se foge à regra quanto às exigências acerca do conhecimento e reputação de seus membros. Exige-se que o membro do TPI tenha um vasto conhecimento em vários ramos do Direito. O mínimo que se exige é o conhecimento em matéria de Direitos Humanitários e Direito Internacional. Além destas exigências, o membro do tribunal precisa dominar, pelo menos, duas línguas das que são oficiais da Corte (BRASIL, 2002) ${ }^{4}$.

\section{PRINCIPIOLOGIA DO TRIBUNAL PENAL INTERNACIONAL}

Desde logo, faz-se necessário sanar um recorrente equívoco: não é incomum a confusão dos leitores entre a aplicação do Direito Penal propriamente dito e Direito Penal Internacional. $\mathrm{Na}$ verdade, estas matérias coadunam-se. A dúvida surge porque 0 Tribunal Penal Internacional julga obedecendo a princípios cujos são encontrados também no Direito Penal brasileiro (conforme o Capítulo III do Estatuto de Roma). Logo, não se aplica a Lei Penal pátria a esta Corte, mas julga-se respeitando a lei interna.

Nesse diapasão, Neves e Streifinger (2012, p. 210-211) complementam que:

[...] ao analisar o Estatuto de Roma, deve-se ter em mente princípios atrelados aos Direitos Humanos e ao Direito Internacional, e não uma lógica jurídica interna. Nesse propósito, repita-se o que se firmou quando da

\footnotetext{
${ }^{4}$ As línguas árabe, chinesa, espanhola, francesa, inglesa e russa são as línguas oficiais do TPI (Art. 50 do ERTPI).
} 
ratificação do Estatuto de Roma, entendendo-se que no conflito entre normas internacionais e internas, em matéria de Direitos Humanos, há sempre a prevalência da norma que favoreça a dignidade da pessoa humana [...]. Assim, aceitar o Estatuto de Roma não significa supressão de direito fundamental de uma pessoa, mas sim um acréscimo protecionista da dignidade da pessoa humana, que favorece não só o indivíduo, mas a toda a Humanidade.

No TPI, julga-se dando atenção a vários princípios. Eis alguns:

I) Complementariedade (preâmbulo e art. 10 do ERTPI) - trata-se do principal princípio da Corte, onde atua como instituição derradeira. $\mathrm{Na}$ hipótese de o Estado abdicar ou não conseguir punir o sujeito, seja por ineficácia de sua legislação ou por grau de risco que corre quem o julga, a competência passar-se-á ao Tribunal Penal Internacional.

II) Vedação do ne bis in idem (art. 20 do ERTPI) - se o sujeito outrora foi julgado por outro Tribunal pelo mesmo crime, tendo sido condenado ou não, o TPI estará proibido de julgálo.

III) Menoridade (art. 26 do ERTPI) - o TPI não tem jurisdição no que tange aos menores de 18 (dezoito) anos de idade. Leva-se em conta a idade que o sujeito tinha quando praticou $o$ crime.

IV) Imprescritibilidade (art. 29 do ERTPI) os crimes dos quais versa o Estatuto de Roma não prescrevem, podendo ser levados ao TPI a qualquer tempo.

V) Universalidade (art. 120 do ERTPI) - o Estado submete-se integralmente ao TPI, não se admitindo reservas ou mitigações na aplicabilidade de suas normas.

Por fim, vale destacar que os demais princípios são tidos como comuns de Direito, quais sejam, legalidade, juiz natural, anterioridade, in dubio pro reo, entre outros.

\section{O ESTATUTO DE ROMA E A CONSTITUIÇÃO FEDERAL DE 1988}

Viu-se que o TPI é regido pelo Estatuto de Roma. Neste há previsão do réu ser condenado à prisão perpétua, banimento ou extradição, além de outras ${ }^{5}$. De fato, é possível de se observar que há incompatibilidades entre o Estatuto do TPI e a $\mathrm{CF} / 88$.

A Constituição Pátria adota, como cláusulas pétreas, em seu art. 5ㅇ, a impossibilidade de pena morte, salvo em caso de guerra declarada ${ }^{6}$; pena de caráter perpétuo; e de banimento. Não obstante, há a proibição de extradição de brasileiro nato. (BRASIL. Constituição, 1988)

Esses aparentes conflitos de normas não são vislumbrados somente no direito brasileiro, mas no de vários Estados membros do TPI. Diante disto, a doutrina explica que:

[...] a resistência,
manifestada por vários
países, em aceitar a
universalidade dos direitos
humanos é obstáculo
ponderável para a sua
institucionalização
internacional. Afinal, em
uma situação de predomínio
do relativismo não teria
sentido a institucionalização
internacional dos direitos
humanos. A realização de
diálogos interculturais, que
identifiquem constelações
axiológicas comuns nas
diferentes culturas, é a única
forma apta a propiciar a
consolidação dos elos sociais
que definem, em última
instância, a eficácia
internacional dos direitos
humanos. (AMARAL JUNIOR,
2012, p. 239)

Cumpre ressaltar que o Tribunal Penal Internacional não pode atuar em todos os casos, mas somente quando o Estado não possuir meios necessários ou for insuficiente a sua legislação acerca do crime (complementariedade). Considerando-se isto, havendo previsão de tal crime no rol do Estatuto, passar-se-á então à competência da Corte.

\footnotetext{
${ }^{5}$ O Estatuto de Roma do Tribunal Penal Internacional (Decreto n.으 4.388, de 25-09-2002) não aplica pena de morte.

${ }^{6}$ Cf. O Código Penal Militar (Decreto-lei n.o 1.001, de 21-10-1969) prevê a pena de morte (arts. 55 a 57). (BRASIL, 1969).
} 
Em resumo, a referida Corte, formada a partir de densos estudos por vários países, promete conservar a sociedade internacional de todo o constrangimento que lhe é imposto, visto que ainda há um jogo de acasos, onde "[...] parece determinar ora a criação de instâncias ad hoc ora o empenho avulso de alguma jurisdição nacional em ter diante de si determinado estrangeiro acusado de crime ocorrido no exterior, sem conexão alguma com o foro" (REZEK, 2011, p. 186).

\section{CONCLUSÃO}

Generalizando-se, a finalidade da criação do TPI é de atender a uma necessidade cujos Estados não tenham, eventualmente, aptidão para saná-la e, ao mesmo tempo, não interferir na soberania dos mesmos, visto que não se impõe a obrigação de aderir ao seu Estatuto.

O mundo possui um Tribunal Penal Internacional, autônomo, permanente e de grande importância aos direitos humanos, tão debatidos ultimamente. Tribunal este que não viola direitos nem ocasiona a supremacia da punição de indivíduos; que deve ser conhecido e estudado por todo bom operador do direito; que - diga-se de maior importância aos brasileiros sua nação faz parte desta conquista; que traz um grande simbolismo da boa relação internacional que a República Federativa do Brasil tem, o que não deixa de ser um dos respeitáveis princípios constitucionais (art. 4. da CF).

Assim, um Estado soberano cooperar com uma Corte que prioriza os direitos humanitários representa a hegemonia constitucional de prevalecer a dignidade da pessoa humana, que é o mínimo que se exige para se apresentar um Estado Democrático de Direito.

\section{REFERÊNCIAS}

ACCIOLY, $\mathrm{H}$. et al. Manual de direito internacional público. 22. ed. São Paulo: Saraiva, 2016.

AMARAL JUNIOR, A. do. Manual do candidato: noções de direito e direito internacional. 4. ed. Brasília: Fund. Alexandre Gusmão, 2012.

BIANCHINI, A.; GOMES, L. F. (Coord.). Saberes do direito: direito internacional público. São Paulo: Saraiva, 2012. v. 55.

BRASIL. Constituição (1988). Constituição da República Federativa do Brasil. Brasília: Senado Federal, 1988.

BRASIL. Decreto-Lei n.o 1.001, de 21 de outubro de 1969. Código Penal Militar. Diário Oficial da União,
Brasília, DF, 21 out. 1969. Disponível em: $<$ www.planalto.gov.br/ccivil__03 /Decreto-Lei/Del 1001.htm>. Acesso em: 12 mar. 2016.

BRASIL. Decreto n.o 4.388, de 25 de setembro de 2002. Dispõe sobre o estatuto de Roma do Tribunal Penal Internacional. Diário Oficial da União, Brasília, DF, 26 set. 2002. Disponível em: <www.planalto. gov.br/ccivil_03/decreto/2002/D4388.htm>. Acesso em: 18 fev. 2016.

BRASIL. Emenda Constitucional n. .945 , de 8 de dezembro de 2004. Altera dispositivos dos arts. 5. ${ }^{\circ}$, $36,52,92,93,95,98,99,102,103,104,105,107$, $109,111,112,114,115,125,126,127,128,129,134$, e 168 da Constituição Federal, e acrescenta os arts. 103-A, 103-B, 111-A e 130-A, e dá outras providências. Vade Mecum. 4. ed. São Paulo: Saraiva, 2014.

TRINDADE, Antônio Augusto Cançado. Os tribunais internacionais contemporâneos. Brasil: FUNAG, 2013.

NEVES, C. R. C. ; STREIFINGER, M. Manual de direito penal militar. 2. ed. São Paulo: Saraiva, 2012.

REZEK, Francisco. Direito internacional público: curso elementar. 13. ed. São Paulo: Saraiva, 2011.

Recebido para publicação em 02/08/2016

Revisado em 03/08/2016

Aceito em 18/08/2016 